International Journal of Arts and Humanities Studies (IJAHS)

ISSN: 2754-4311

DOI: $10.32996 /$ ijahs

Journal Homepage: www.al-kindipublisher.com/index.php/ijahs

\title{
Temporality in Great Expectations and Mrs. Dalloway: A Comparative Study
}

\author{
Ashraf Abu-Fares
}

The University of Jordan, Amman, Jordan

$\square$ Corresponding Author: Ashraf Abu-Fares, E-mail: ashraf.abufares@yahoo.com

\section{ARTICLE INFO}

Received: 15 September 2021

Accepted: 11 October 2021

Published: 23 October 2021

DOI: 10.32996/ijahs.2021.1.1.2

\section{KEYWORDS}

Temporality; chronological order; narrative structure; consciousness; Dickens; Woolf

\section{ABSTRACT}

The purpose of this paper is to discuss temporality in Charles Dickens's novel Great Expectations and Virginia Woolf's Mrs. Dalloway. Temporality is an integral element in a literary text that greatly reflects the style an author adopts to represent the narrative framework and thematic concerns. However, there is a distinction in how traditional novelists and modern novelists deal with temporality. The events in Great Expectations are presented in a chronological order built on cause and effect. On the other hand, the narrative in Mrs. Dalloway is presented using the "stream of consciousness"; in the thoughts and feelings of the characters. Nonetheless, in Great Expectations, chronological order offers the plot unity and comprehension. It is also crucial in developing the theme of formation and development of the protagonist. In contrast, in Mrs. Dalloway, the experience of temporality is offered and shared by most characters. The reader is required to examine this experience to form a perception of the narrative structure and the themes of the novel. Therefore, this paper makes a comparative analysis between Great Expectations and Mrs. Dalloway to highlight the distinction between how traditional novels and modern novels deal with temporality to present the narrative and embody their authors' concerns.

\section{Introduction}

"Fiction is like a spider's web, attached ever so slightly

perhaps, but still attached to life at all four corners."

\section{- Virginia Woolf - A Room of One's Own}

Novels are one type of fiction that contrives representations of human life through prose. Novels have elements distinguishing them as a literary genre. Basically, novels present their narratives through a device called the "story" or "plot." A writer of a novel constructs the story based on a mere idea. As an illustration, Pride and Prejudice by Jane Austen is a novel which its author develops as a story of "a young couple destined to be married having first to overcome the barriers of pride and prejudice" (Burgess, 2020). Nevertheless, any weaving of a certain idea requires ingenuity and fidelity from its author because the plot of one novel needs to be someway distinct from that of another.

Another element in novels is characterization. A skilled novelist focusses on how characters may be created in a more unique way than a conventional novelist does. This can be found in James Joyce's Ulysses and Laurence Stern's Tristram Shandy. One more element in all novels is narrative method or point of view. Novelists use various methods and narrators to narrate their stories. In Ulysses, for instance, Joyce uses multiple narrators in his novel, and most of them are unreliable narrators.

Other elements in a novel include length, setting and symbolism. However, one of the most significant elements in a novel is temporality. Novelists vary in how they deal with temporality in their works. While some novelists adhere to a chronological order in telling their narrative, many others disrupt it, offering new perspectives to narrate and read a novel. It is this element in a novel that this paper highlights. In what follows, there is a discussion of how traditional and modern novelists deal with

Copyright: (C) 2021 the Author(s). This article is an open access article distributed under the terms and conditions of the Creative Commons Attribution (CC-BY) 4.0 license (https://creativecommons.org/licenses/by/4.0/). Published by Al-Kindi Centre for Research and Development, London, United Kingdom. 
temporality in their novels. To achieve this purpose, two novels are taken as illustrations: Great Expectations by Charles Dickens, representing traditional novels, and Mrs. Dalloway by Virginia Wolf, represesnting modern novels.

\section{Review of Related Literature}

Great Expectations is the thirteenth novel of Charles Dickens. It is a bildungsroman, or a coming-of-age novel, which is a classic work of Victorian literature. It portrays the personal development of an orphan, Pip, who is adopted by a blacksmith's family. The narrative follows his childhood and young adult years in a country village, as one who has good luck and great expectations. He suddenly comes into a large fortune (his great expectations) from a mysterious benefactor and moves to London where he enters high society. Then he loses both his luck and expectations. Thus, the novel records this rise and fall of the protagonist and how he learns to find happiness and reaches maturity and self-recognition in the end (Definitions, "Great Expectations", 2020).

Mrs. Dalloway is Virginia Woolf's novel, published in 1925. It is one of Woolf's best-known novels. It provides details of a day in the life of Clarissa Dalloway, a woman from high-society who inhabits in post-First World War England. The novel highlights Clarissa's preparations for a party she will host in the same evening. Through an interior perspective, the story moves forward and backwards in time and out of the character's minds to construct an image of Clarissa's life and the inter-war social structure (Definitions, "Mrs. Dalloway", 2020).

Dickens' novel - Great Expectations - has been studied by many researchers from several angles. In his article, "The work of love: Great Expectations and the English Bildungsroman", Matthew Taft (2020) suggests that Dickens uses the Bildungsroman as a form to show that the aspiration to transcend the world of labor transforms the everyday life of an ordinary individual as Pip. Money transforms social ties and the Bildungsroman naturalizes the conflict between a system of social organization where each generation would step into the shoes of the preceding one and another in which each generation desires to transcend the one before. Taft concludes that as we look at Great Expectations as negotiating a major rift in the relation between the inner world of the individual and the world of objects, we can perceive that Dickens's disfiguration of the form can be seen to presage the emerging professional ruling class who reconcile upward mobility and love through servicing others.

Tang Tingting and Liu Lihui (2015) deal with the spatial construction as a main feature of Dickens' Great Expectations. They show how the spatial conversion has an impact on the cognitive development of the protagonist, Pip, from the viewpoint of space production. There is a three-dimension space in the novel and each of these dimensions affects Pip's value orientation. In addition, culture and apace interact together and influence Pip's cognitive development. As a prominent feature in the novel, space has a huge impact on the development of the plot, characters' psychology and Pip's cognition.

Likewise, many studies have discussed Woolf's novel - Mrs. Dalloway - from a variety of perspectives. In an article titled "Mrs. Dalloway's Dialogic Discourse and the Function of the Written Fragment," Christine Smoley (2015) discusses how Woolf utilizes Bakhtin's theory of dialogism in her novel and constructs the narrative from multiple 'voices' granting it dialogic form. Woolf emphasizes that life experiences are ideally perceived as not finalized nor yielding to a 'materialistically' conclusive mode of representation, which nevertheless is the most truthful. Similarly, Bakhtin proposes that a discourse loses its essence when confined to stylistic considerations. The novel has a dialogic form through interacting with other social and cultural paradigms, only achieved when there is no 'finalising' textual authoritative voice closing possible readings. Likewise, Woolf asserts that an ideal reader for a dialogic text like Mrs. Dalloway gets inclined to interpret a complete meaning upon ending it.

Nariman Larbi (2019) explores the use of the "stream of Consciousness" in Woolf's Mrs. Dalloway as a twentieth-century psychological concept that has been accommodated into fictional exertion through the Interior Monologue. Larbi points out that Woolf is chief among the first practitioners who engaged with this technique as modernist fictional writers with what previous novelists of the nineteenth century failed to engage with. Larbi indicates that as Woolf experiments in her texts with the inner psyche of the characters and the permanence of the past the present beyond the reach of realism, her fiction tends to be psychological. Therefore, Woolf deals in her fiction with complex networks of emotions and memories of which the character is the center of the narrative. Larbi shows how the stream of consciousness is utilized in this novel "to show and uncover the anxieties vis-à-vis her thanatophobia, not only this, but also to express the anxieties of the Great War and the disillusionment towards the modern enterprise" (178).

However, this study is different from previous studies as it discusses the aspect of temporality in the two novels together, Great Expectations and Mrs. Dalloway. There has not been any study that combines the two novels explored in this research together and analyzes them in terms of the features of temporality. This is the first time this topic is attempted in a research paper in this way. Therefore, it is hoped that this paper will make a contribution in the field of comparative studies and add to the understanding of the distinctions between traditional and modern novels concerning the vital element of temporality. 


\section{Research methodology}

This research uses the qualitative method to achieve its objective. This method is suitable since the results are introduced in a descriptive manner. The study also adopts the analytical and critical method in interpreting and analyzing the two novels explored here. Furthermore, data is gathered from multiple resources, consisting of primary and secondary ones. The primary resources are comprised of Charles Dickens's novel, Great Expectations and Virginia Woolf's Mrs. Dalloway. In addition, the research utilizes secondary sources related to the topic, including books, articles and some internet websites.

\section{Results and Discussion}

\section{1. Temporality in Great Expectations}

Novels are identified as traditional when they adhere to a variety of conventional methods to present their narratives. Most traditional novels present their narratives in accordance with a chronological order of time. In Aspects of the Novel, E. M. Forster (1974) suggests that the backbone of a novel is the story it contains. He defines the story as "a narrative of events arranged in their time-sequence; dinner coming after breakfast, Tuesday after Monday, decay after death, and so on" (Forster, 1974, p. 42). This is the simplest element relevant to a story and the basic factor common to all novels.

In relation to this, Paul Ricoeur (1984) believes in the existence of chronological time which may correspond to the number of pages and lines in a work. Ricoeur deals with what Muller, one critic, suggests regarding the method of presenting the narrative in relation to time. "The initial narrative schema is that of sequence, and the art of narrating consists in restoring the succession of events" (qtd. in Ricoeur, 1984, p. 79).

Furthermore, some critics believe that there is a double-edged structure for depicting life in the novel: the life in time and the life by values. Forster (1974) believes that "daily life whatever it may be really, is practically composed of two lives- the life in time and the life by values and our conduct reveals this double allegiance: (I saw her for five minutes but it was worth it" (Forster, 1974, p. 42-43). The novel includes the life by values as well as using various devices. But the allegiance to time in the novel is imperative while it may not be so in daily life.

Ricoeur (1984) also suggests that the relation of the time of narration to the time of life through narrated time is an important aspect. The reference to life in a narrative is crucial to comprehend the time of narrative and the narrated time the same as in the work of formation or transformation; Bildung, Umbildung (Ricoeur, 1984, p. 80). This highlights how the adherence to time in a novel is a basic element in most traditional novels.

Great Expectations, by Charles Dickens, is an example of traditional novels where time sequence is a basic element. The events in this novel are told by the protagonist, Pip, following a sequential order. In the beginning, Pip tells about his mistreatment by Miss Havisham and the humiliation he receives from Estella. Then he describes his apprenticeship with Joe. After that, he narrates the news of his great expectations becoming true until he loses his fortune. Towards the end, he describes his self-maturity and success, and how he somehow approaches reconciliation with his beloved, Estella. Therefore, we see an obvious adherence to chronological order, where the events are almost subsequent to each other. This is also important since most events cause other aspects to take place in Pip's life and lead to his growth and maturity, especially with this novel being a Bildungsroman.

A. H. Gomme (1971) argues that most of Dickens's works, and in particular, Great Expectations and Hard Times, are introduced in a way in which their plots are developed consistently. "In fact, Dickens's plots rather often seem the work of a manufacturer of fiction. Hard Times and Great Expectations are the clearest exceptions, in which not only are the plots coherently and consistently developed retaining their own compelling and single minded interest in their author: plot and theme are consummately fused" (Gomme, 1971, p. 91).

Similarly, Barbara Hardy (1988) suggests that in this novel Dickens is interested in portraying events and incidents and even the very minute details through following a chronological sequence of time, although some incidents are narrated using recollection and memory (Hardy, 1988, p. 38). In relation to this, Kate Flint (1986) argues that there is what she calls "double logic" in the novel which works throughout and shows the great unity of the novel provided by a first-person narrative. This may be attributed to the fact that the plot of the novel is presented through sequences of events that depend on a process of cause and effect (Flint, 1986, p, 51). As a good illustration, Pip's desire to become a gentleman seems to be a consequence of Estella's mistreatment for him and his will to please her. Also, Miss Havisham urges Estella to react towards Pip in a way which fulfills Miss Havisham's revenge to the other sex.

Thus, on the one hand, Great Expectations follows a sequential order to tell its events. On the other hand, by doing this, this novel hugely succeeds in depicting the growth of the protagonist. Hardy (1988) describes this: "As so often in Dickens, the 
outline of development and conversion is firm and plain..." (Hardy, 1988, p. 32). Gomme (1971) also suggests that Great Expectations is a profound illustration for this, among many novels for Dickens. "By contrast, the excellence of Great Expectations lies in the accuracy with which the plot registers the steady development of the central theme - the growth from moral ignorance to wisdom, which in a true first-person's narrative must be a matter of self-discovery" (Gomme, 1971, p. 179).

Throughout the novel, Pip is mistreated by the society around him, which makes him feel inferior, and suffers from the lack of support from others. In addition, he has many obstacles in his way. Meantime, he makes his way in his new career and feels that some opportunity would rise for him. He goes through a process of self-ignorance until he reaches self-discovery and knowledge. No doubt this is one major factor why the novel is classified among Bildungsroman novels; novels that depict the development and change of the protagonist after struggling towards self-realization and fulfillment of wills.

There are many occasions in the novel that show how Pip's character changes continuously and how he reaches towards maturity and self-recognition. For example, telling about his reunion with Magwitch after being caught by the police, Pip says:

[M]y convict looked round him for the first time, and saw me ... I looked at him eagerly when he looked at me, and slightly moved my hands and shook my head. I had been waiting for him to see me, that I might try to assure him of my innocence. It was not at all expressed to me that he even comprehended my intention, for he gave me a look that I did not understand, and it all passed in a moment. But if he had looked at me for an hour or for a day, I could not have remembered his face ever afterwards as having been more attentive. (Great Expectations, 2000: p. 32-33)

This suggests one of the changes in Pip's character. Pip has been interested for a long time in how people react to his own behavior. However, in this situation, Pip is very keen on having Magwitch to realize that Pip is innocent and is not responsible for the capture of Magwitch by the police. However, the look Magwitch has at Pip does not indicate that he has perceived Pip's innocence or guilt. It is a look that Pip "did not understand", but is the most "attentive" look Pip has ever got. Actually, this suggests that Pip's kindness has resulted in the strong feelings of love and devotion that Magwitch comes to have.

Another example on Pip's development and approaching towards self-recognition and maturity is the scene in which Pip tells Magwitch as he lays dying about the latter's daughter, Estella, whom Magwitch has not seen since she was a young girl:

"Dear Magwitch, I must tell you, now at last. You understand what I say?"

A gentle pressure on my hand.

"You had a child once, whom you loved and lost."

A stronger pressure on my hand.

"She lived and found powerful friends. She is living now. She is a lady and very beautiful. And I love her!"

(Great Expectations, 2000: p. 404)

In this scene, Pip comforts Magwitch with the fact about Estella. With this, Pip demonstrates how far he has matured and formed a new understanding of what really matters in life. Instead of insisting on the idealistic hierarchy of social class that has been essential in how Pip viewed life, we find Pip at this moment having the ability to realize hierarchy as superficial and ineffective in assessing a character. There are other factors like loyalty, love and inner goodness that are more important for him than these social labels. This is a decisive thing that Pip explicitly recognizes by identifying the hindrances that stood before in the way of his true understanding of the world.

\section{2. Temporality in Mrs. Dalloway}

In modern novels, there is a plain shift from using conventional techniques and narrative methods. Also, there is a change in how novelists treat time in their works. While traditional authors believe in the significance of time sequence, modern writers almost neglect it and even disrupt and shatter it. This tendency stemmed from the change in how scientists and philosophers started to comprehend temporality in modern times.

Among those who no more believed in the significance of chronological time or "clock time" is the French philosopher Henri Bergson. Bergson believes that time is actually presented to consciousness and duration as an endless process, not by observing objects and events in succession. Therefore, duration is one element which is important to perceive the experience of time and that of existence. According to Stephen Linstead and John Mullarkey (2003), Bergson does not believe in the traditional way of viewing time in relation to space or sequences, Bergson believes in real time that he calls 'duration', which "is a creativity whereby a new and unpredictable entity appears at each and every moment. The components of duration (our memories, perceptions and affections) are all different, yet they also interpenetrate and cannot be sharply distinguished" (Linstead \& Mullarkey, 2003, p. 6). 
Furthermore, according to Bergson, consciousness is another crucial medium through which time is experienced. Consciousness enables a person to keep changing by experiencing every situation in a new perspective each time he or she interacts with it. Moreover, Bergson believes that time is perceived by intuition which is a component of duration. According to him, it brings us to the continuity of duration which we must try to follow.

Influenced by scientists and philosophers such as Freud and Bergson, modern novelists started writing literary works that deal with time without following chronology and that focus on the human mind and psychology. Authors shifted from presenting the narrative as a succession of events which moves in a sequential order and portrays external action, to present the narrative through the psyches and thoughts of its characters without adhering to time-sequence, but rather shattering time and giving it other perspectives to present and comprehend the narrative.

William James is one American philosopher who came up with the concept of "the stream of consciousness," which became a narrative technique that authors used in their writings. This technique signifies the narrative method by which an author attempts to capture the flow of a character's thought, often in a series of separate and apparently unrelated passages that when looked at together give an impressionist view of reality as seen by that character. James believes in the significance of consciousness as an element needed to perceive existence and comprehend time (Ellman and Feidlson, 1965, p. 134). Other authors who were influenced by the experience of time through disregarding its sequential order include T. S. Eliot who came up with the concept of "objective correlative". This concept entails a series of objects, events or images that are not put in a chronological order, but the author uses them to provide an effect on the reader when they are put or linked together.

Among many modern novels, Virginia Woolf's Mrs. Dalloway significantly depicts various aspects of modernism in the English novel. In particular, it is a remarkable example which illustrates how modern novelists deal with temporality in their works. The story in this novel is not told following a chronological order. Woolf uses the "stream of consciousness" as a narrative method. The narrative is presented through the mind and psyche of characters such as Clarissa, Mrs. Dalloway, and her first lover, Peter Walsh. Ricoeur (1984) argues that the narrator in this novel who knows the thoughts of all the characters from the inside has the ability to move from one stream of consciousness to another by having the characters meet in the same places as London streets and public parks and be presented in the same incidents (Ricoueur, 1984, p. 104).

Therefore, the narrative in Mrs. Dalloway is not presented in a chronological order; as readers, we have to assimilate it from the consciousnesses of several characters and how they feel about incidents and about each other. A good example of the thoughts of the characters which appear throughout the novel is when the narrator says:

It is probably the Queen, thought Mrs. Dalloway, coming out of Mulberry's with her flowers; the Queen. And for a second she wore a look of extreme dignity standing by the flower shop in the sunlight while the car pasted at a foot's peace, with its blinds drawn. The Queen going to some hospital, the Queen opening some bazaar, thought Clarissa. (Mrs. Dalloway, 1996, p. 89-90)

Furthermore, the use of the consciousness and thoughts of the characters to tell the story has its effects on the narrative. Since the story is not told following time-sequence, the result is that time is fragmented and shattered. According to Christine Smoley (2015), there are many discourses in Mrs. Dalloway that demonstrate a fragmented, elliptical signification or an unconventional displacement of meaning. One of these characters is Septimus. Using Ancient Greek, a 'dead language,' the bird's message is meaningful within Septimus' reality. Therefore, its meaning for him cannot be understood by receiving the significance of Greek 'words' literally. He finds the "supreme secret" through interpreting them without rules of language governing its signifying function (Smoley, 2015, p. 207). Septimus's discourse is absent within the textual world; much of it presenting his reality is conveyed through indirect discourse. His writings are fragments and lack value to express truth, showing the futility of language for him and futile attempts at communication.

Nevertheless, by freeing itself from sticking to a linear aspect of time, Mrs. Dalloway shows that the narrative structure in the novel is designed in a way which enables the narrator to offer the reader an amount of temporal experience to share, which is, meantime, the basis for the experience that its characters have. For instance, the details and incidents which accompany the party that Clarissa holds mark the culmination and the closure of the narrative. In particular, the plot is composed of these elements which accompany the party; besides, there is the news of the suicide of Young Septimus a few hours before the party which is another focal point in the plot. This also has an effect on the reader to reevaluate and think about what is presented. As Smoley (2015) suggests, "Mrs. Dalloway requires the reader to read between the lines, or rather, between the voices, to form an understanding of the message or the meaning of the text" (Smoley, 2015, p. 205). 


\section{Conclusion}

As the analysis has shown, there is a distinction in how traditional novelists and modern novelists deal with time in their novels. Most traditional novelists adhere to time-sequence in telling their narratives. Great Expectations, a traditional novel by Charles Dickens, is a novel in which the events are presented in accordance with a chronological order which seems to be built on a process of cause and effect. On the other hand, modern novelists show a deviation from sequential time in presenting their narratives. They tell the story by means of the characters' minds and psyches. Mrs. Dalloway, a modern novel by Virginia Woolf, is told through the use of the "stream of consciousness" as a narrative method. The story is presented throughout the novel in the thoughts and feelings of the characters.

However, the adherence to time-sequence offers advantages to the novel. In the case of Great Expectations, chronological order helps in offering the plot unity and comprehension. As well, it is crucial in developing the theme of formation and development of the protagonist's personality as in most Bildungsroman novels to which this novel belongs. On the other hand, in modern novels, as a result of neglecting time order, time is shattered and constantly the narrative structure tends to be fragmented. Meantime, this offers new perspectives for both the characters in the novel and for readers. In Mrs. Dalloway, the experience of time is offered and shared by most characters. The reader is required to examine the experience of time in the novel in order to form a perception of the narrative structure and the themes of the novel.

\section{Acknowledgement}

I would like to express my special thanks and gratitude to Professor Yousef Abu Amrieh, University of Jordan, Jordan, for his invaluable support in writing this research paper. I would also like to thank my family who extensively encouraged me all the way through.

\section{About the author}

Ashraf Abu-Fares is a specialist in English literature. He has more than ten years of academic experience, teaching at university level. He is currently a PhD candidate in English Literature at The University of Jordan, Amman, Jordan. His research interest is mainly in the fields of the English novel, literary theory and cultural studies. He has written a group of research papers published in international scholarly journals. His recent articles include "Truth in Nietzsche's and Dostoevsky's Philosophy: A Comparative Study", "A Bakhtinian Reading of Joseph Conrad's Heart of Darkness" and "Representations of Death in Rawi Hage's Beirut Hellfire Society".

\section{References}

[1] Burgess, A. (2020, November 5). novel | Definition, Elements, Examples, Types, \& Facts.Encyclopedia Britannica. https://www.britannica.com/art/novel> Accessed 10 Nov. 2020.

[2] Dickens, C. (2000). Great Expectations. Beirut: York Press

[3] Flint, K. (1986). Dickens. Brighton: The Harvester Press Ltd.

[4] Forster, E. M. (1974). Aspects of the Novel. London: Clays Ltd, St Ives plc.

[5] Gomme, A. H. (1971). Dickens. London: Evans Brothers Ltd.

[6] "Great Expectations." (2020). Web. Definitions.net. STANDS4.LLC， <https://www.definitions.net/definition/great+expectations> Accessed 25 Nov. 2020.

[7] Hardy, B. (1968). Dickens: The Later Novels. Harlow: Longman Green \& Co.

[8] Larbi, N. (2019). A Literary Voyage into the Unconscious: A Philosophical Approach to the Psychological Novel in Woolf's Mrs. Dalloway (1925). Arab World English Journal for Translation \& Literary Studies, 3 (3) 178-187. DOI: http://dx.doi.org/10.24093/awejtls/vol3no3.14

[9] Linstead, S. \& Mullarkey, J. (2003). Time, Creativity and Culture: Introducing Bergson. Culture and Organization, 9(1), 3-13.

[10] Matthew, T. (2020). The work of love: Great Expectations and the English Bildungsroman, Textual Practice, 34(12), 19691988, DOI: 10.1080/0950236X.2020.1834700

[11] "Mrs Dalloway." (2020). Web. Definitions.net. STANDS4. LLC, <https://www.definitions.net/definition/mrs+dalloway> Accessed 25 Nov. 2020.

[12] Ricoeur, P. (1984). Time and Narrative. Vol. 2. Chicago: University of Chicago Press.

[13] Smoley, C. (2015). Mrs. Dalloway's Dialogic Discourse and the Function of the Written Fragment. Transcultural Studies, 11, $199-215$.

[14] Tang, T. T., \& Liu, L. H. (2015). Pip's Cognitive Development in Great Expectations From the Viewpoint of Space Product. Studies in Literature and Language, 10 (1), 51-57, DOI: http://dx.doi.org/10.3968/6339

[15] Woolf, V. (1996). Mrs. Dalloway. London: Penguin Popular Classics. 